\title{
THE EFFECT OF CHEMICAL KINETICS AND RADIATION ON FLAME RADIUS AND TEMPERATURE PREDICTION OF UNSTEADY SPHERICAL DIFFUSION FLAMES IN MICROGRAVITY - A COMPARISON WITH EXPERIMENTS
}

\author{
S. Berhan, M. Chernovsky, S. Filatyev, A. Atreya \\ Department of Mechanical Engineering \& Applied Mechanics \\ University of Michigan; Ann Arbor, MI 48109 \\ and \\ KURT R. SACKSTEDER \\ NASA Glen Research Center; Cleveland, $\mathrm{OH} 44135$
}

\begin{abstract}
$\underline{\text { Abstract }}$
The results of experimental measurements on transient spherical diffusion flames in microgravity are compared with numerical calculations using infinite rate, finite rate single-step and finite rate multi-step descriptions of chemical kinetics. In all calculations, except for the analytical model using infinite-rate kinetics, emission approximation was made for modeling the flame radiation. The experimental measurements consist of Flame radius, Flame temperature, and Flame radiation for various fuel flow rates of $\mathrm{CH}_{4}, \mathrm{C}_{2} \mathrm{H}_{4} \& \mathrm{C}_{2} \mathrm{H}_{2}$ in air with ambient $\mathrm{O}_{2}$ concentration. The objective of the experiments and modeling is to understand how chemical kinetics and flame radiation affect the flame growth rate, temperature and extinction properties.
\end{abstract}

It was found that radiative heat loss substantially slows the flame radius growth rate. Flame radiation was also found to drop the flame temperature by more than $500 \mathrm{~K}$ in some cases. Despite this large temperature drop radiative extinction was not achieved in these experiments. However, numerical calculations with only gas radiation show that radiative extinction is possible by enhancing the combustion products concentration. Numerically, it was also found that radiative heat loss causes the gas inside the spherical flame to cool increasing its density. Thus, the spherical flame collapses resulting in a reversal in the gas velocities near the flame zone. Detailed chemical kinetics description was found to have only a small effect on the flame radius \& flame temperature predictions. However, it is extremely important to understand the extinction mechanisms.

\section{Introduction}

The absence of buoyancy-induced flows in microgravity $(\mu g)$ and the resulting increase in the reactant residence time significantly alters the fundamentals of many combustion processes. Substantial differences between normal gravity $(n g)$ and $\mu g$ flames have been reported in experiments on candle flames [1,2], flame spread over solids [3, 4], droplet combustion $[5,6]$, and others. These differences are more basic than just in the visible flame shape. Longer residence times and higher concentration of combustion products in the flame zone create a thermochemical environment that changes the flame chemistry and the heat and mass transfer processes. Processes such as flame radiation, that are often ignored in $n g$, become very important and sometimes even controlling. Furthermore, microgravity conditions considerably enhance flame radiation by: (i) the build-up of combustion products in the high-temperature reaction zone which increases the gas radiation, and (ii) longer residence times make conditions appropriate for substantial amounts of soot to form which is also responsible for radiative heat loss. Thus, it is anticipated that radiative heat loss may eventually extinguish the Aveak@low burning rate per unit flame area) $\mu g$ diffusion flame. Yet, space shuttle experiments on candle flames show that in an infinite ambient atmosphere, the hemispherical candle flame in $\mu g$ will burn indefinitely [1]. This may be because of the coupling between the fuel production rate and the flame via the heat-feedback mechanism for candle flames, flames over solids and fuel droplet flames. Thus, to focus only on the gas-phase phenomena leading to radiative extinction, aerodynamically stabilized gaseous diffusion flames are examined. This enables independent control of the fuel flow rate to help identify conditions under which radiative extinction occurs. Also, spherical geometry is chosen for the $\mu g$ experiments and modeling because: (i) It reduces the complexity by making the problem one-dimensional. (ii) The spherical diffusion flame completely encloses the soot which is formed on the fuel rich side of the reaction zone. This increases the importance of flame radiation because now both soot and gaseous combustion products co-exist inside the high temperature spherical diffusion flame. (iii) For small fuel injection velocities, as is usually the case for a pyrolyzing solid, the diffusion flame in $\mu g$ around the solid naturally develops spherical symmetry. Thus, spherical diffusion flames are of interest to fires in $\mu g$ and identifying conditions that lead to radiation-induced extinction is important for spacecraft fire safety. 


\section{Experiments}

The experiments were conducted in the $2.2 \mathrm{sec}$ drop tower at the NASA Glenn Research Center. The drop-rig used is described in detail elsewhere [7]. Briefly, it consists of a cylindrical test chamber (0.38m dia.; $0.43 \mathrm{~m}$ deep) that houses the spherical burner, the hot-wire igniter and the photodiodes and thermocouples used for making radiation and temperature measurements. The spherical burner (19mm dia.) was constructed from a low heat capacity porous ceramic material (93\% porosity). Two gas cylinders $(150 \mathrm{cc} \& 500 \mathrm{cc})$ were charged with various gases up to $45 \mathrm{psig}$ and were used to supply the fuel to the porous spherical burner. Fuel flow rates to the burner were controlled by a calibrated needle valve and a gas solenoid valve was used to open and close the gas line to the burner upon computer command. The test chamber also had a $125 \mathrm{~mm}$ diameter Lexan window which enabled the

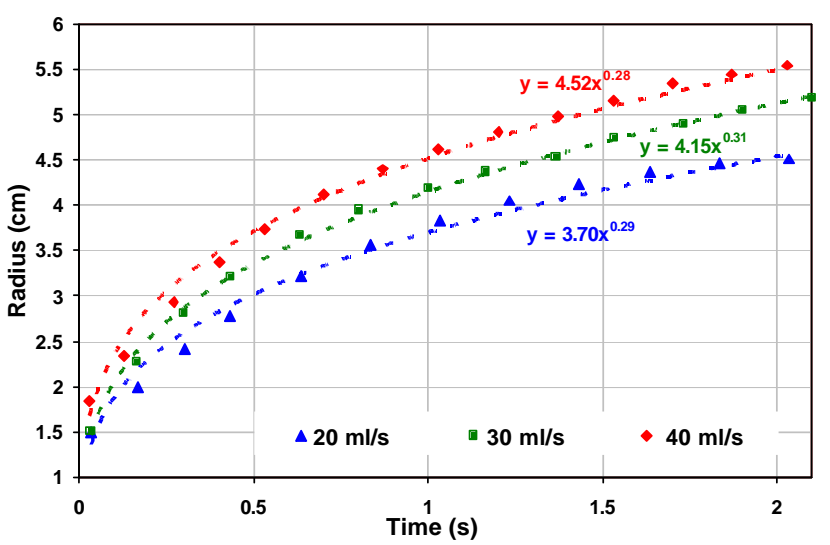

Figure 1: Methane Radius Measurements

camera to photograph the flame.

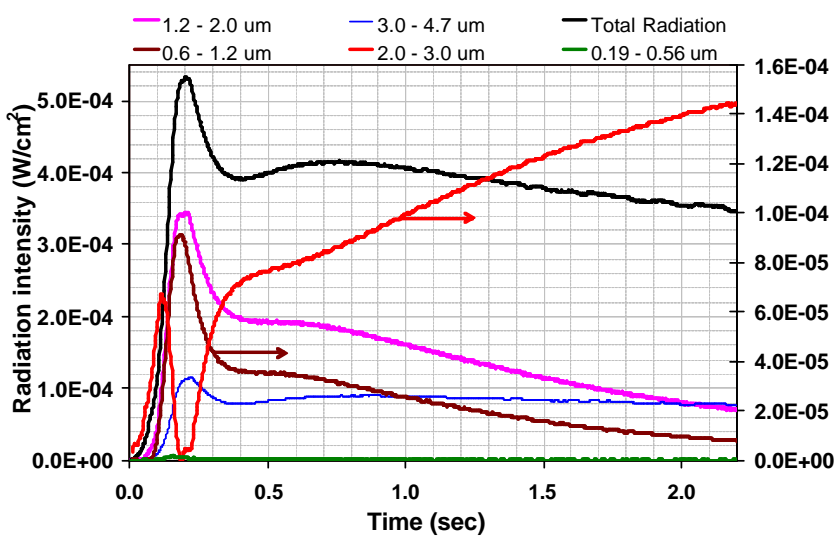

Figure 2: Acetylene $45 \mathrm{ml} / \mathrm{s}$ - Radiation Measurements

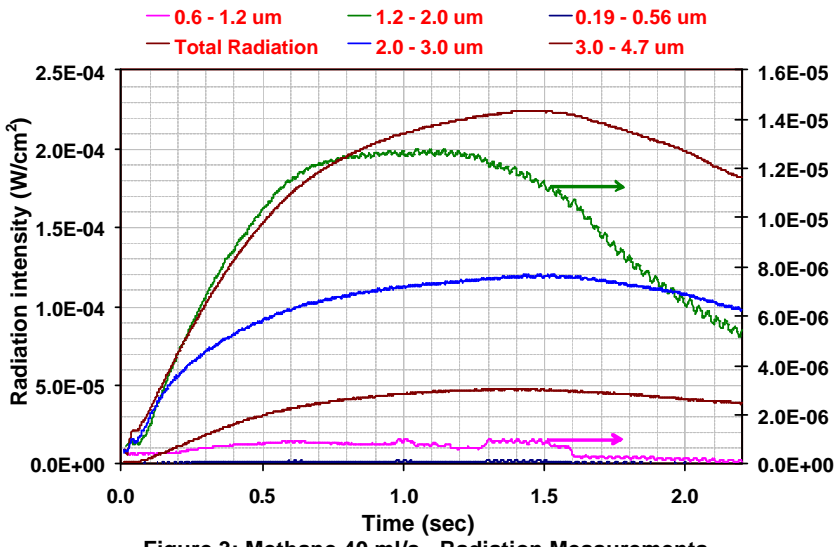

Figure 3: Methane $40 \mathrm{ml} / \mathrm{s}$ - Radiation Measurements

Several $\mu g$ experiments under ambient pressure and oxygen concentration conditions, were conducted

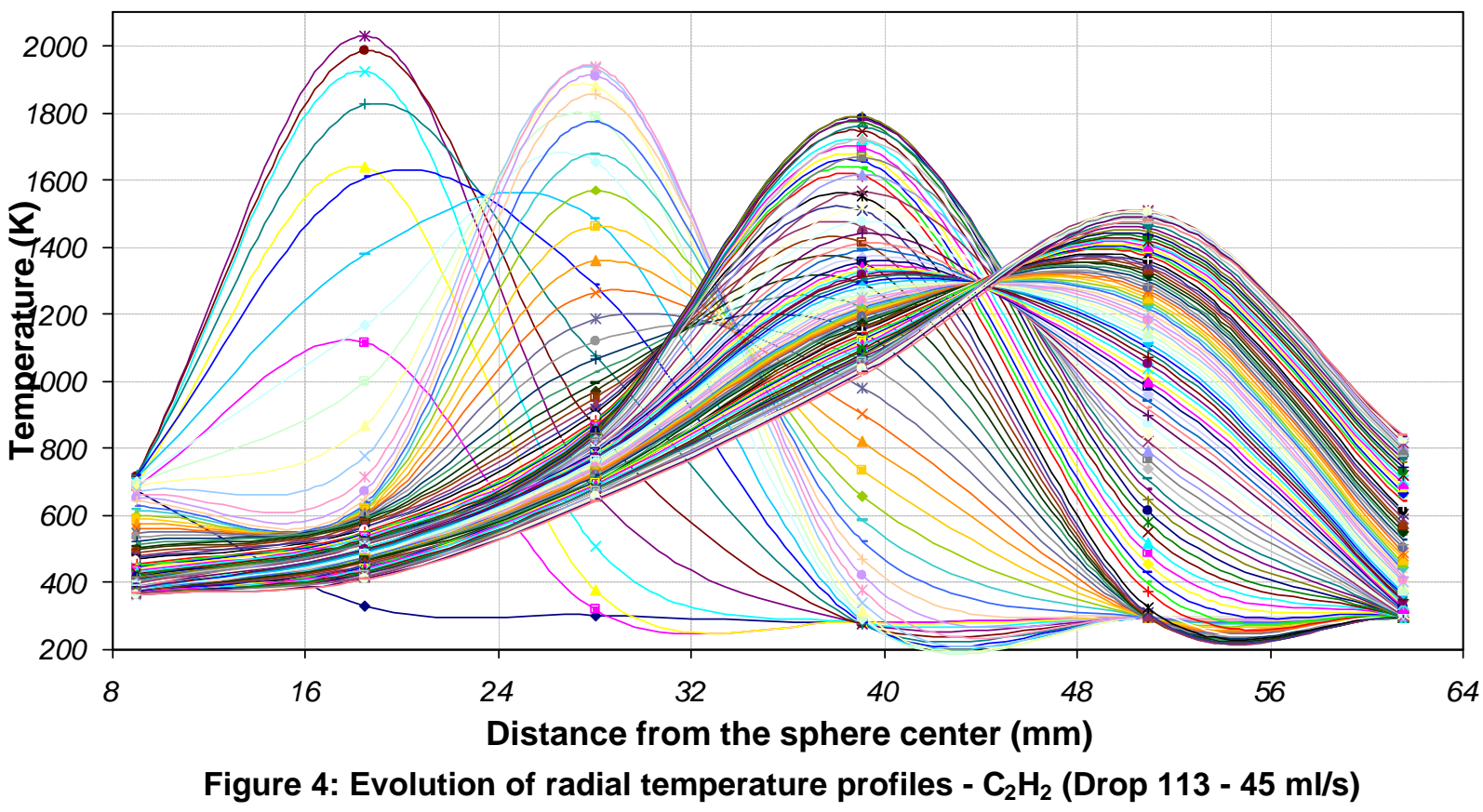


with methane (less sooty), ethylene (sooty), and acetylene (very sooty) fuels for flow rates ranging from 3 to $45 \mathrm{~cm}^{3} / \mathrm{s}$. Only a few results are presented here. The data was collected by an onboard computer during the drop and the following measurements were made: (i) Flame radius - measured from photographs taken by a color CCD camera (see Figure 1 for three experiments on methane at different flow rates). (ii) Flame radiation - measured by photodiodes with different spectral characteristics ranging from UV to IR (See figures $2 \& 3$ for comparable flow rates of acetylene and methane. Here, the radiation emitted by the flame in different wavelength intervals is plotted). (iii) Flame temperature - measured by five S-type thermocouples and the sphere surface temperature was measured by a K-type thermocouple. The evolution of radial temperature profiles is shown in Figure 4 for an acetylene flame.

Experimental Observations: Video photographs show that for all fuels (methane, ethylene and acetylene), initially the flame was blue (non-sooty) but becomes very bright yellow (sooty) under $\mu g$ conditions. Later, as the $\mu g$ time progresses, the flame grows in size and becomes orange and less luminous and the soot luminosity disappears. For the same fuel flow rate, methane flames eventually become blue (non-sooty) in approximately one second, ethylene flames became blue toward the end of the $\mu g$ time (i.e. $\approx 2 \mathrm{sec}$ ) while acetylene flames remained luminous yellow throughout the $2.2 \mathrm{sec} \mu g$ time. However, the luminosity of acetylene flames was considerably reduced toward the end of the $\mu g$ time and would have also become blue given more time.

A possible explanation for this observed behavior is suggested by the measurements of soot of Ref.[8] and theoretical calculations of Ref.[9]. The soot measurements of Ref.[8] clearly show that the amount of soot decreases with increase in the combustion products concentration. The calculations of Ref.[9] also show that the soot volume fraction first quickly increases and later decreases. Essentially, at the onset of $\mu g$ conditions, initially a lot of soot is formed in the vicinity of the flame front resulting in a very bright yellow emission. As the flame grows, several events reduce the flame luminosity: (i) The high concentration of combustion products left behind by the flame front inhibits the formation of new soot and promotes soot oxidation. (ii) The primary reaction zone, seeking oxygen, moves away from the soot region and the soot is pushed toward the cooler regions by thermophoresis. Both these effects increase the distance between the soot layer and the reaction zone resulting in the formation of a soot shell. (iii) The dilution and radiative heat losses caused by the increase in the concentration of the combustion products reduces the flame temperature which in turn reduces the soot formation rate and the flame luminosity.

These visual observations are in agreement with the flame radiation measurements shown in Figures 2
\& 3 for $\mathrm{C}_{2} \mathrm{H}_{2}$ \& $\mathrm{CH}_{4}$ respectively. Radiation for $\mathrm{CH}_{4}$ flames (Fig. 3) gradually increases and then decreases. This is true not just for the visible radiation but also for the infrared radiation containing the major $\mathrm{CO}_{2}$ and $\mathrm{H}_{2} \mathrm{O}$ bands. Clearly, the flame gases are cooling at a rate faster than the combustion heat release. Given sufficient time the flame is expected to extinguish. However, the situation is different for acetylene flames. First, the flame radiation is significantly larger due to soot formation and oxidation in the vicinity of the high temperature reaction zone. This is responsible for the large rise and decrease in the first 0.4 seconds. As time proceeds, the radiation from all wavelengths decreases except radiation from the 2$3 \mu \mathrm{m}$ band which contains the combined $\mathrm{CO}_{2}$ and $\mathrm{H}_{2} \mathrm{O}$ bands. The 3-4.7 band, corresponding to $\mathrm{CO}_{2}$, however, stays constant but shows a slight peak for $\mathrm{t}<0.4 \mathrm{sec}$. Since the combined $\mathrm{CO}_{2} \& \mathrm{H}_{2} \mathrm{O}$ band dips considerably in this zone, it implies that the increase in radiation is primarily due to soot oxidation. Later, as the distance between the soot shell and the reaction zone increases, only $\mathrm{H}_{2}$-rich species are burning resulting in an increase in the $\mathrm{H}_{2} \mathrm{O}$ band radiation. It would be interesting to calculate the $\mathrm{H}_{2}, \mathrm{H}_{2} \mathrm{O}$ and $\mathrm{CO}_{2}$ $\mathrm{CO}$ and $\mathrm{OH}$ profiles in this region. Figure 4 provides the radial temperature distribution corresponding to Figure 2. Clearly, the flame temperature continuously falls and we expect even acetylene flame to extinguish given sufficient time.

To better understand these processes and predict flame radius, radiation and temperature, theoretical models are being developed with chemical kinetics and flame radiation. As a first step, soot formation and oxidation is not included and three types of models are considered: (i) Assuming infinite reaction rate (analytical), (ii) Assuming a single-step reaction mechanism, and (iii) Using a skeletal reaction mechanism from Smooke[10]. Also, emission approximation was made in all cases for modeling the flame radiation.

\section{Model Formulation}

As noted above, the spherical diffusion flames are expanding and changing their luminosity with time. Thus, the general theoretical formulation must be transient and must include flame radiation. For the simplest case of constant pressure ideal gas reactions, we may write the following governing equations:

\section{Mass Conservation:}

$$
\frac{u}{x}+\nabla \cdot(\rho \vec{v})=0
$$

\section{Energy Conservation:}

$$
\rho \frac{\partial h^{s}}{\partial t}+\rho \vec{v} \vec{\nabla} h^{s}-\vec{\nabla} \cdot\left(\rho D \vec{\nabla} h^{s}\right)
$$


Species Conservation:

$$
=-\sum_{i} h_{t}^{0} W_{t}-Q_{s} \dot{m}_{s_{o}}^{m}-\vec{\nabla} \cdot \vec{q}_{r}
$$

$$
\rho \frac{\partial Y_{t}}{\partial t}+\rho \vec{v} \cdot \vec{\nabla}\left(Y_{t}\right)-\vec{\nabla} \cdot\left[\rho D \vec{\nabla}\left(Y_{t}\right)\right]=w_{t}
$$

\section{Constant Pressure Ideal Gas:}

$$
\rho T=\rho_{\infty} T_{\infty} \quad \text { or } \quad \rho h^{s}=\text { const } .
$$

Here, the symbols have their usual definitions with $\rho=$ density, $\mathrm{T}=$ temperature, $v=$ velocity, $\mathrm{Y}_{\mathrm{i}}=$ mass fraction of species $\mathrm{i}, \mathrm{h}^{\mathrm{s}}=$ sensible enthalpy, $\mathrm{w}_{\mathrm{i}}=$ mass production or destruction rate per unit volume of species i and $D=$ diffusion coefficient. The last three terms in Equ. (2) respectively are: the chemical heat release rate due to gas phase combustion, chemical heat released due to soot oxidation and the radiative heat loss rate per unit volume. The above equations, however, are insufficient for our problem because the soot volume fraction must be known as a function of space and time to determine the radiative heat loss.

Under conditions of small soot loading, as in the case of methane, the soot terms in the fuel and energy conservation equations are ignored. This is done to enable developing an analytical model. Thus, species and energy equations are replaced by a mixture fraction variable ' $\mathrm{Z}$ ' which is described by a homogeneous equation. The expectation is that this approach may be adequate for calculating the observed expansion rate of the spherical diffusion flames, but it is expected to be completely inadequate for predicting radiative extinction. However, the great mathematical advantage of this approach is that it makes Eqs. ( $2 \& 3)$ identical and only one conserved scalar equation need be considered. Re-writing the above equations in spherical coordinates, we get:

\section{Mass Conservation:}

$$
\frac{\partial \rho}{\partial t}+\frac{1}{r^{2}} \frac{\sigma}{\partial r}\left(r^{2} \rho v\right)=0
$$

\section{Fuel Conservation:}

$$
\rho \frac{\partial Z}{\partial t}+\rho v \frac{\partial Z}{\partial r}-\frac{1}{r^{2}} \frac{\partial}{\partial r}\left(r^{2} \rho D \frac{\partial Z}{\partial r}\right)=0
$$

These two equations along with the ideal gas law at constant pressure, Equ.(4), are sufficient to approximately describe the transient growth of spherical diffusion flames. Defining a stream function ' $\psi$ ' to identically satisfy Equ. (5), we get:

$$
\frac{\partial \psi}{\partial t}=-r^{2} \rho v ; \frac{\partial \psi}{\partial r}=r^{2} \rho ;-\left(\frac{\partial r}{\partial t}\right)_{\psi}=v
$$

The corresponding initial and boundary conditions for a sphere of radius ' $R$ ' blowing fuel gases at a rate

are discussed below and illustrated in Figure 5.

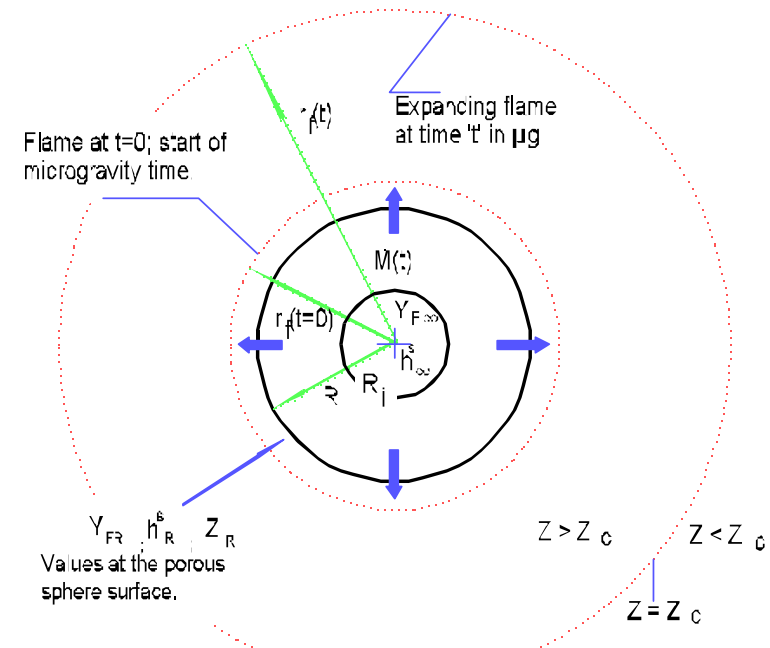

Figure 5: Schematic of the Model Problem

Applying initial and boundary conditions we get:

$$
\begin{aligned}
\Psi(r, t) & =\int_{\substack{R(t=0) \\
t}}^{r(t)} r^{2} \rho(r, t) d r-\frac{M(t)}{4 \pi} \\
& =\int_{t=0}^{r} r^{2} \rho(r, t) v d t+\rho_{-}\left(\frac{r^{3}-R^{3}}{3}\right)
\end{aligned}
$$

Where $M(t)$ is the total fuel mass that has been injected from the sphere in time ' $t$ '. For a constant given mass injection rate $\dot{M}(\boldsymbol{t}), M(t)=\dot{M}(t) \times t$. Now rewriting Equ.(6) in terms of ' $\psi$ ' we obtain:

$$
\frac{\partial Z}{\partial t}=p_{\infty}^{2} D_{\infty} \frac{\partial}{\partial \psi}\left(r^{4} \frac{\partial Z}{\partial \psi}\right)
$$

In deriving the above equation $\rho^{2} D$ has been assumed constant. At $r=r_{f}$, i.e. the flame location, our previous work [7] shows that:

$r_{f}(t)=\left(\frac{3 M(t)}{4 \pi \rho_{f}}+R^{3}\right)^{\frac{1}{3}}$

Thus, solving Equ. (9) with $r=r_{f}$ we obtain the distribution of ' $\mathrm{Z}$ ' around the flame. The flame 
location is given by $\psi=0$ and $Z=Z_{C}$. The ' $Z$ ' distribution is given by:

$$
Z=\frac{1-\operatorname{erf}\left(\frac{\psi}{2 \sqrt{\tau}}\right)}{1+\operatorname{erf}\left(\frac{M(t)}{8 \pi \sqrt{\tau}}\right)}
$$

And, the flame location is given by:

$$
r_{f}(t)=\left(R^{3}+\left(\frac{3 \dot{V}\left(p_{o} h_{-}^{s}+Q p_{o} Y_{m_{\omega}} Z_{c}\right)}{4 \pi\left(p_{0} h_{-}^{s}+\bar{\eta} t\right)}\right) \times t\right)^{1 / 3}
$$

Here ' $R$ ' is the radius of the initial igniting flame or in our case the porous sphere and ' $\hat{\eta}$ ' is the average radiative heat loss from the flame per unit volume. While Equ (12) is very approximate, it captures the physics of flame growth. This equation was used to normalize the measured flame radius data. The results are shown in Figure 6. The fact that most of the data falls along a constant value $(\sim 1.3)$ is very encouraging. Furthermore, the numerical calculations with one step reaction mechanism and thin gas radiation also falls along this constant value. Numerical calculations without radiation clearly do not agree with the data.

Figure 7 shows that as far as the flame radius predictions are concerned, a detailed mechanism is not necessary. However, figures $8 \& 9$ show how $\mathrm{OH}$

mass fraction and temperature is reduced at extnction.

Acknowledgements: This project was supported by NASA under the Contract No.: NCC3-482.

\section{$\underline{\text { References }}$}

1. Dietrich, D. L., Ross, H. D. and T'ien, J. S. "Candle Flames in Microgravity," Third Microgravity Combustion Workshop, Cleveland, Ohio, April, 1995.

2. Ross, H. D., Sotos, R. G. and T'ien, J. S., Combustion Science and Technology, Vol. 75, pp.155-160, 1991.

3. T'ien, J. S., Sacksteder, K. R., Ferkul, P. V. and Grayson, G. D. "Combustion of Solid Fuels in very Low Speed Oxygen Streams," Second International Microgravity Combustion Workshop," NASA Conference Publication, 1992.

4. Ferkul, P., V., "A Model of Concurrent Flow Flame Spread Over a Thin Solid Fuel," NASA Contractor Report 191111, 1993.

5. Jackson, G., S., Avedisian, C., T. and Yang, J., C., Int. J. Heat Mass Transfer., Vol.35, No. 8, pp. 2017-2033, 1992.

6. Tsue, M., Segawa, D., Kadota, T. and Yamasaki, $H$. Twenty-Sixth (International) Symposium on Combustion, The Combustion Institute, 1996, pp. 1251-1258.

7. Atreya, A, Agrawal, S., Sacksteder, K., and Baum, H., "Observations of Methane and Ethylene Diffusion Flames Stabilized around a Blowing Porous Sphere in :g Conditions," AIAA \# 94-0572.

8. Zhang, C., Atreya, A. and Lee, K., Twenty-Fourth (International) Symposium on Combustion, The Combustion Institute, pp. 1049-1057, 1992.

9. Atreya, A. and Agrawal, S., "Effect of Radiative Heat Loss on Diffusion Flames in Quiescent Microgravity

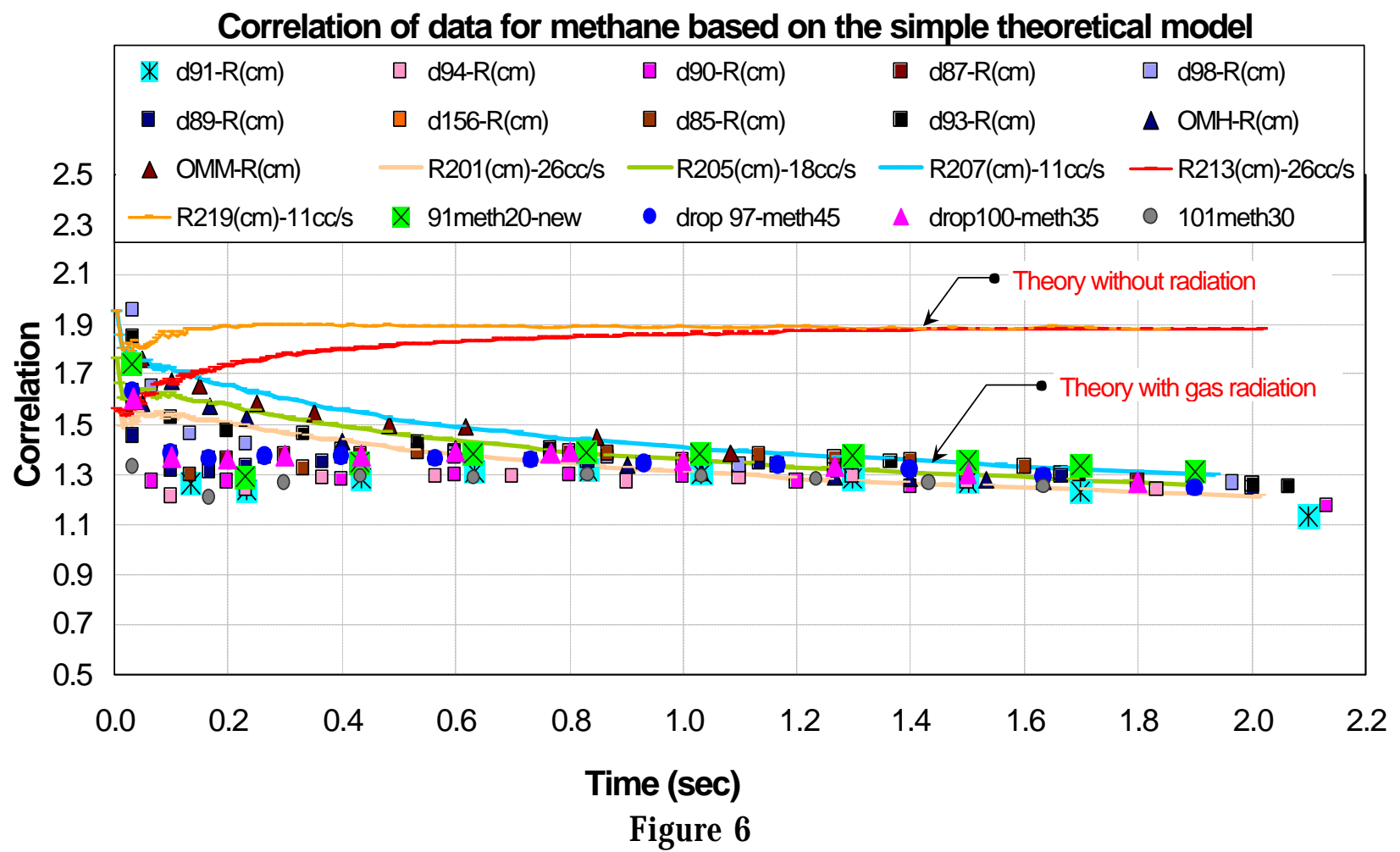




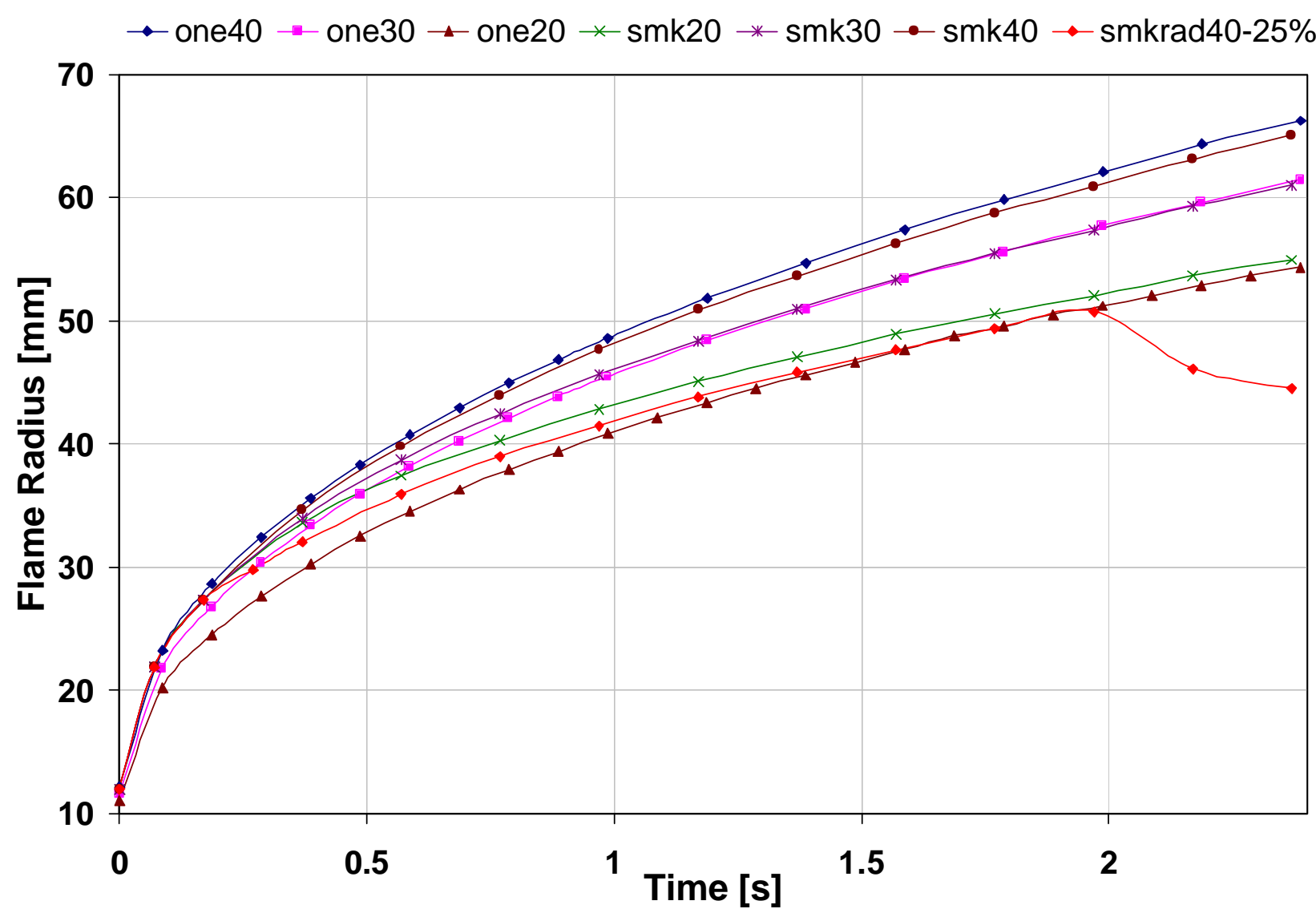

Figure 7: A comparison of detailed chemistry calculations using Smooke's[10] skeletal mechanism with one step reaction for prediction of flame radius of methane flames.

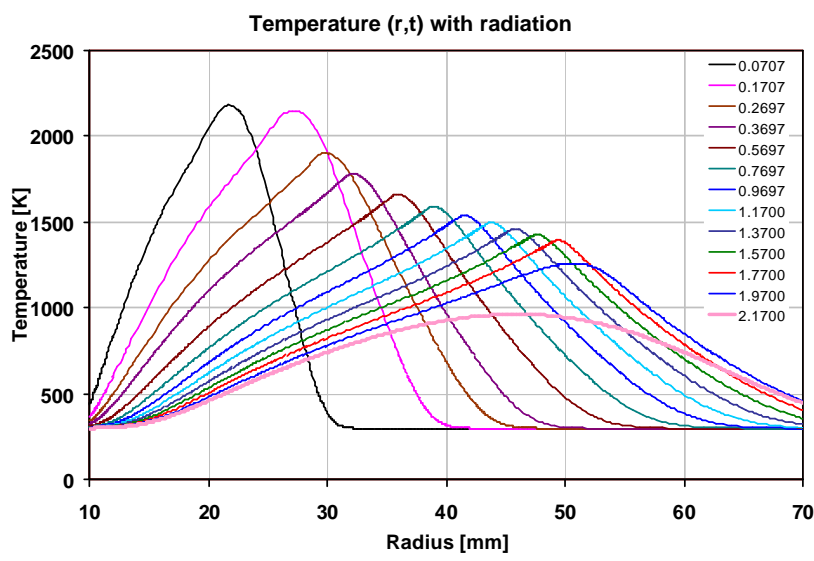

Figure 8: Decrease in the flame temperature due to radiation - Smooke's mechanism [10]

Atmosphere," Combustion \& Flame, p372-382, v115, 1998.

10. Smooke, M. D.(ed.) "Reduced Kinetic Mechanisms and Asymptotic Approximations for Methane-Air Flames," Springer-Verlag, 1991.

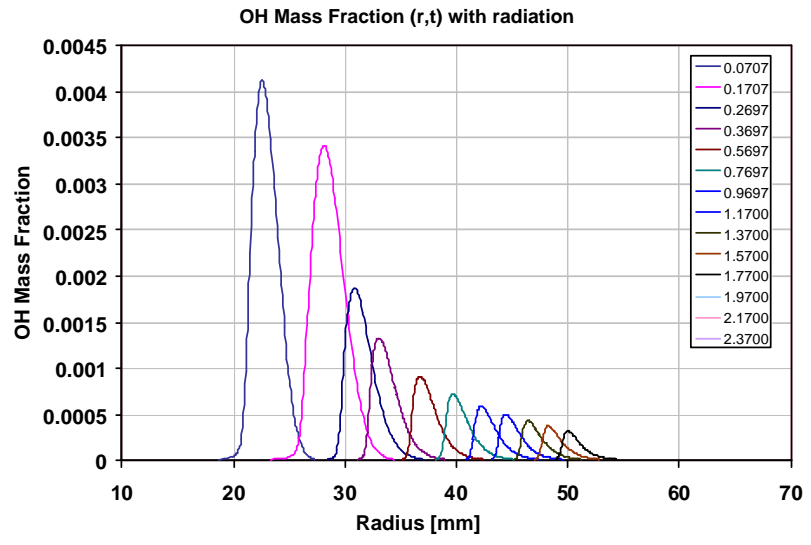

Figure 9: Decrease on $\mathrm{OH}$ mass fraction as the flame tends towards extinction. 